\title{
A comparative study of family impact in children with attention deficit hyperactivity disorder (ADHD) and learning disability
}

\author{
Henal Shah ${ }^{1}$, Karishma Rupani $^{2}$, Sayantani Mukherjee ${ }^{3}$, Ravindra Kamath ${ }^{4}$ \\ ${ }^{1}$ Professor, \\ ${ }^{2,3}$ Resident Doctor, \\ ${ }^{4}$ Professor and Head, \\ Department of Psychiatry, BYL Nair Charitable Hospital and Topiwala National Medical College, Mumbai. \\ E-mail-k.i.rupani@gmail.com
}

\begin{abstract}
Background : Parents of children with ADHD/ Learning Disability (LD) have high levels of stress and lack of familiarity with their child's disorder resulting in a significant impact on their lives; we studied this impact and it's correlation with illness, socio demographic variables, attribution of disorder and social support.

Methodology : A cross-sectional comparative study was done in a municipal tertiary care centre; 50 mothers each of children with ADHD and LD recruited from child psychiatry OPD and 50 mothers of non-referred children from Paediatric OPD. Data regarding sociodemographics and attribution collected from their interview along with scores from scales applied (Family Impact Questionnaire - Revised; Multidimensional Scale for Perceived Social Support) were compared and analyzed.

Results : A more significant impact was found with ADHD than in LD; worse impact in ADHD was observed with hyperactive subtype, lack of knowledge about disorder, lower socio-economic strata, larger family size, having more family members with same disorder and lower social support. In LD, impact is greater when there is lack of knowledge and attribution is to perceived child characteristics (suggesting intentionality).

Conclusions : The results of our study imply that in the Indian context the overall impact due to both $\mathrm{ADHD}$ and LD are at par as academics are given as much priority as respectful behaviour. However, this impact is affected by certain variables which are subject to through change through intervention. These are illness, socio demographic variables, perceived support by the family and parental attribution of their child's disorder. Thus interventions addressing the feasible variables at individual, family and community levels can lessen this impact.
\end{abstract}

Keywords: Attention Deficit Hyperactivity Disorder, ADHD, Specific Learning Disorders, family impact, factors affecting family impact

\section{INTRODUCTION}

Attention Deficit Hyperactivity Disorder (ADHD) and Specific Learning Disorders (LD) are 'invisible' disorders where the affected children, despite appearing normal, show scholastic backwardness as well as behavioural problems, causing significant stress in their families. This stress, in the Indian society, is further compounded by the fact that we place a very high premium on both academic excellence as well as courteous and respectful behaviour in children [1].

Family dysfunction in relation to communication, problem solving and relationships has been noticed in families with children who have a diagnosis of ADHD [2], leading to a 
host of limitations within multiple domains of life, including family relationships, sibling relationships, peer relationships and school functioning. Its high prevalence, chronic course and substantial impact on daily life functioning for children, their parents, peers, and teachers have made it a major public health concern [3].

The impact on family of having a LD child also is substantial. Parents of children with LD have significantly higher stress level as compared to non-referred as shown by previous studies [4]. The marital relationship between parents, relationship with siblings and the family's social support and finances all get negatively impacted leading to a poorer quality of life for the family of the LD child [5]. The child's condition creates a continual pressure on the family and therefore the child is usually viewed more negatively and found to be more difficult to live with as compared to normal children; there is resulting disruption of family relationships causing more marital stress in parents, more social stress and poor social support for the family, degradation in the siblings' quality of life as well and a substantial dent in the family's finances in providing for the child's special needs [6]. Despite this issue being quite pertinent, at least in the urban Indian setup, we did not find any Indian studies on this topic and a few international studies.

Therefore, we decided on conducting this study so as to understand the family impact and the role of factors affecting it such as social support, illness and socio demographic variables and attribution of illness.

\section{METHODOLOGY}

Mothers (as they are the primary caregivers) of children with LD/ADHD (of age 8 to 12 years) were the subjects of the study. The study aimed to document the impact of LD/ ADHD on the family and the factors affecting this impact on them, viz. illness variables, socio-demographic variables, attribution of the disorder and their perceived social support.

Our inclusion criteria included mothers of child ( 8 to 12 years) diagnosed exclusively with either LD (tested by Woodcock Johnson -III test and Wechsler Intelligence Scale for Children [WISC]) or ADHD (as per DSM IV-TR criteria) using a multi disciplinary approach comprising of detailed assessment of the child, in the referred group by a psychiatrist, psychologist, special educator, occupational therapist and a paediatrician. Mother of non-referred child ( 8 to 12 years) i.e. child who is not LD or ADHD formed the control group. The children of the non referred group were screened using criteria of DSM-IVTR for ADHD [7]. For assessment of LD the mother was asked regarding history of difficulty reading (including poor comprehension), writing (reversals, omissions, additions in writing) and difficulty in mathematics (calculations, difficulty in the language of math) resulting in scholastic backwardness as observed by her or as reported by the school. This group comprised children having a non-life-threatening and non-chronic illness (e.g. upper respiratory tract infections, diarrhoea etc. and all such other disease of non-serious nature where the patient's long-term health is not grossly compromised, lasting for short duration from which the child is most likely to make a full recovery and will not have any significant, lasting impact on the child or her/his family). The children included were judged clinically to be having average or above average intelligence. The mothers were questioned for any developmental delays, history of scholastic backwardness or failures to gauge the intelligence of the child. Children with developmental delays and history of poor academic problems were excluded in the non referred group. For children of the LD and ADHD group, a WISC and a clinical assessment of intelligence were done respectively.

The inclusion criteria were mothers willing to participate and give informed consent were included in the study. Our exclusion criteria consisted of mothers of child of age less than 8 years or more than 12 years, those whose children had co-morbid child mental illnesses (e.g. mental retardation/ autism) Exclusion of other mental disorders were done using our clinical assessment. Mothers with children who had other chronic illness (e.g. tuberculosis, bronchial asthma, polio etc. and other such disease which are of serious nature as they would grossly compromise patient's long-term health and would have a lasting impact on the child and her/ his family) and also mothers not willing to give informed consent were excluded. 
This study was a cross-sectional comparative study design conducted after obtaining permission from the Institutional Ethics Committee. After a baseline evaluation, 50 consecutive mothers were chosen as participants for each group (LD/ ADHD/ non-referred). Mothers of children (age 8-12 years) diagnosed with LD/ ADHD by a multi-disciplinary team were recruited from Psychiatry child services. Mothers of non-referred children i.e. non-LD/ ADHD children with non-threatening non-chronic illnesses (age 8-12 years) were recruited from the Psychiatry child clinic / Paediatrics out patients department (OPD). The mothers were interviewed by single interviewer only. For the specific purpose of this study we assessed the mothers as they usually are the primary care-givers to the child, spend most time with and are most intimately involved with all the aspects of the child's life and therefore are the most impacted when it comes to dealing with the pressures of raising a child with special needs.

The interview consisted of a semi-structured proforma which including socio-demographic variables, illness variables and questions assessing maternal attribution (to factors of hereditary disorders, ante/perinatal factors, environmental problems or perceived child characteristics) of the children's illness. Data analysis was done with the help of statistical software (SPSS version 15) and Sigma Plot (Version 11). Results were presented in the form of percentage and frequency tables. Quantitative data was analyzed with the help of Kruskal Wallis and Anova test for comparison between three groups. The test of significance applied was as per the results of normality testing. Quantitative data was analyzed with the help of Mann-Whitney test for comparison between two groups. Qualitative data analysis was done with the help of Chi square test. Correlation between quantitative variables was done with spearman correlation coefficient. A p value less than 0.05 was taken as statistically significant.

The tools used in the study were -

(1) Semi-structured proforma - It consisted of questions regarding socio demographic variables, illness variables and questions assessing the mothers' attribution of their child's illness to above mentioned factors.

(2) Family Impact Questionnaire - Revised (FIQ-R) [8] - It is a 50-point questionnaire given by Geri Donenberg and Boyle to assess the impact the children with illnesses/ special needs have on the life of their parents. The reliability is $0.66-0.83$ and its validity is high. This scale is qualitative with 7 subscales with both positive and negative questions. The subscales are overall impact, financial, social, marital, sibling impact, difficulty with living with child and parental attitude. For the purpose of scoring we converted it into quantitative by assigning scores of 1-4 to the four possibilities and scored the positive and negative questions by marking and reverse marking respectively to obtain a total score out of a maximum value of 60 and minimum 6 for each impact. (Higher the score, more negative is the impact). The term impact in this study has a negative connotation and whenever used denotes negative impact.

(3) Multidimensional Scale Of Perceived Social Support (MSPSS) [9] - Zimmet, Dahlem and Farley developed the MSPSS to concisely measure an individual's perceived social support from three support sources i.e. family, friends and her/ his significant other (these consist the three subscales). It is a 12-item scale to be used with a 7-point likert scale. Higher the score, better is the support. Each of the three subscales can be scored out of a maximum value and compared; scores of 16 and below reflect poor social support for each subscale. The reliability is $0.85-0.88$, with strong factorial validity between the three subscales.

\section{RESULTS}

Graph 1 shows us how the perceived social support is divided into three domains as follows with comparison of various dimensions of perceived social support among study group.

Overall impact was significantly and equally (Table1) poor in both ADHD and LD groups as compared to non-referred as per our findings. Our results show a significant difference in parental attitude between all three groups, ADHD having the most negative impact on parental attitude towards their child followed by LD followed by non-referred. 


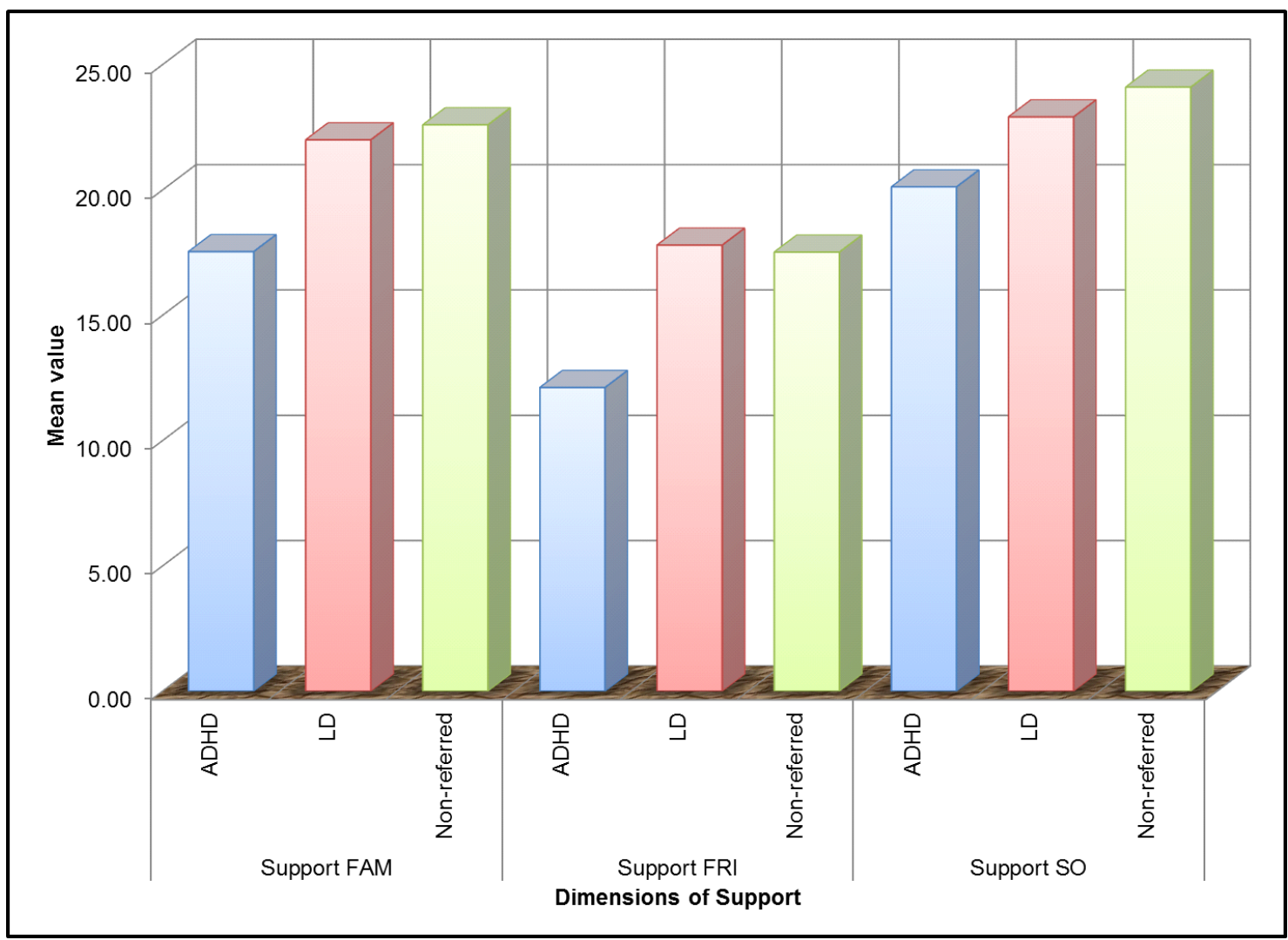

FAM: Family, FRI: Friends, SO: Significant Other

Our results also show a significant and equal impact on the parents' marital life in both ADHD and LD as compared to non-referred. A significant impact on social life of ADHD families as compared to LD and non-referred was noted. However the social impact in LD families is not significantly different and is comparable to non-referred families. A significant difference in financial impact in the descending order between ADHD, LD and the non referred was also seen. Sibling impact shows a significant difference with it being the highest in ADHD whilst the LD and non-referred groups are similar. Degree of difficulty of living with the child was equally significant in both ADHD and LD groups as compared to non-referred (Please refer to Table 1).

Table 1: Comparison of impact among ADHD, LD and non referred

\begin{tabular}{|cccccc|}
\hline & $\begin{array}{c}\text { ADHD } \\
(\text { Mean } \pm \text { SD) }\end{array}$ & $\begin{array}{c}\text { SLD } \\
(\text { Mean } \pm \text { SD })\end{array}$ & $\begin{array}{c}\text { Non referred } \\
(\text { Mean } \pm \text { SD) }\end{array}$ & $\begin{array}{c}\text { Chi Square } \\
\text { test }\end{array}$ & P value \\
\hline Overall impact & $4 \pm 2$ & $3 \pm 2$ & $0 \pm 1$ & 54.98 & $1.15 \mathrm{E}-12$ \\
\hline $\begin{array}{c}\text { Parental } \\
\text { attitude }\end{array}$ & $40 \pm 5$ & $34 \pm 8$ & $24 \pm 4$ & 83.44 & $7.60 \mathrm{E}-19$ \\
\hline Marital impact & $13 \pm 3$ & $12 \pm 3$ & $9 \pm 2$ & 37.42 & $7.47 \mathrm{E}-09$ \\
\hline Social impact & $17 \pm 5$ & $12 \pm 3$ & $12 \pm 3$ & 35.83 & $1.65 \mathrm{E}-08$ \\
\hline $\begin{array}{c}\text { Financial } \\
\text { impact }\end{array}$ & $17 \pm 4$ & $13 \pm 4$ & $10 \pm 2$ & 58.82 & $1.68 \mathrm{E}-13$ \\
\hline Sibling impact & $20 \pm 4$ & $13 \pm 3$ & $12 \pm 1$ & 49.75 & $1.57 \mathrm{E}-11$ \\
\hline $\begin{array}{c}\text { Difficulty living } \\
\text { with child }\end{array}$ & $5 \pm 1$ & $4 \pm 2$ & $2 \pm 2$ & 68.144 & $1.59 \mathrm{E}-15$ \\
\hline
\end{tabular}


The mean for overall impact in the hyperactive-impulsive subgroup was $4 \pm 1.99$ and inattentive subtype was $1.33 \pm 2.07$. Thus there was a statistically significant ( $p 0.004)$ between the two ADHD groups. Almost all the children suffering from LD were co morbid with more than one type of LD and hence could not be compared. Our results show that the lower the socio-economic status, the worse is the impact on the family; this finding however is significant (table 2; p 0.021) only in the ADHD group and not in the LD or non referred group. Our results show a significantly (table $2 ; \mathrm{p} 0.024$ ) higher negative impact in ADHD families when family size is larger (joint family); no such findings are present in the LD group suggesting family size does not have an effect on impact due to LD. Our results show both a significantly (table $2 ; \mathrm{p}$ 0.005) higher overall impact and degree of difficulty of living with child in ADHD families when other family members have same disorder; no such findings are present in the LD group. Our results suggest statistically significant (table $2 ; \mathrm{p}$ 0.004) lesser overall impact if mother has knowledge of child's disorder in both ADHD and LD groups. Also, we found a significantly higher degree of difficulty of living with child in LD mothers who did not have knowledge of their child's disorder in comparison to those who did; no such findings were present in the ADHD group.

Table 2: comparison of factors affecting impact

\begin{tabular}{|cccc|}
\hline \multicolumn{5}{c}{ ADHD } & SLD & \\
\hline & Socio Economic Status & \\
\hline Low & $5 \pm 1$ & $5 \pm 0$ & $0 \pm 1$ \\
\hline Middle & $4 \pm 2$ & $4 \pm 2$ & $0 \pm 1$ \\
\hline High & $2 \pm 3$ & $3 \pm 2$ & $0 \pm 1$ \\
\hline P value & 0.004 & 0.054 & 0.830 \\
\hline & & Family type & $0 \pm 1$ \\
\hline Nuclear & $3 \pm 2$ & $3 \pm 2$ & $1 \pm 2$ \\
\hline Joint & $4 \pm 2$ & $3 \pm 2$ & 0.201 \\
\hline P value & 0.024 & 0.688 & $0 \pm 0$ \\
\hline & Family member with disorder & $0 \pm 1$ \\
\hline Yes & $5 \pm 0$ & $3 \pm 2$ & 0.566 \\
\hline No & $3 \pm 2$ & $3 \pm 2$ & $0 \pm 1$ \\
\hline P value & 0.005 & 0.980 & $1 \pm 2$ \\
\hline & Knowledge of disorder & 0.610 \\
\hline Yes & $3 \pm 2$ & $3 \pm 2$ & $5 \pm 1$ \\
\hline No & $5 \pm 1$ & 0.012 & \\
\hline P value & 0.029 & & \\
\hline
\end{tabular}

Our results (table 3) show a difference in impact in relation to parental attribution of child's disorder. In the LD group parents attributing their child's disorder to their perceived child characteristics (which would suggest a component of intentionality) had a significantly worse impact than parents with the other attributions. No significant differences were found in the ADHD group.

Graph 1 shows, at a glance the perceived social support in all the three domains of social support, which is support from significant other, other family members and friends. Our results (table 4) suggest that perceived social support from significant other, family, and friends is significantly poorer in ADHD group as compared to LD and non-referred groups, which are comparable to each other. The tables show that higher support from significant others and family lessen the overall impact in ADHD group significantly while higher support from family and friends do the same for LD group. 
Table 3: Comparison of attribution among study group with the impact

\begin{tabular}{|c|c|c|c|c|c|}
\hline Group & Impact due to & Mean & Standard Deviation & \multicolumn{2}{|c|}{ Kruskal-Wallis test applied } \\
\hline \multirow[t]{4}{*}{ ADHD } & Hereditary/ brain disorder & 4.86 & 0.73 & $\mathrm{H}$ value & $P$ value \\
\hline & Ante-/ peri-natal factors & 4.36 & 1.39 & 5.68 & 0.128 \\
\hline & Environmental problems & 5.00 & 0.63 & \multirow{2}{*}{\multicolumn{2}{|c|}{ Difference is not significant }} \\
\hline & Perceived child characteristics & 5.29 & 0.83 & & \\
\hline \multirow[t]{4}{*}{ LD } & Hereditary/ brain disorder & 4.06 & 1.56 & $\mathrm{H}$ value & $P$ value \\
\hline & Ante-/ peri-natal factors & 3.89 & 1.32 & 12.49 & 0.006 \\
\hline & Environmental problems & 4.77 & 1.17 & \multirow{2}{*}{\multicolumn{2}{|c|}{ Difference is significant }} \\
\hline & Perceived child characteristics & 5.50 & 0.55 & & \\
\hline \multirow[t]{4}{*}{ Non-referred } & Hereditary/ brain disorder & 1.62 & 1.92 & $\mathrm{H}$ value & $P$ value \\
\hline & Ante-/ peri-natal factors & 0.00 & 0.00 & 9.75 & 0.021 \\
\hline & Environmental problems & 1.43 & 1.99 & \multirow{2}{*}{\multicolumn{2}{|c|}{ Difference is significant }} \\
\hline & Perceived child characteristics & 3.50 & 1.27 & & \\
\hline
\end{tabular}

Table 4: Correlation between overall impact and social support

\begin{tabular}{|lll|}
\hline ADHD group & & \\
\hline support SO out of 28 & Spearman's CC & -0.356 \\
\cline { 2 - 3 } & P value & $0.012^{*}$ \\
\hline support FAM out of 28 & Spearman's CC & -0.473 \\
\cline { 2 - 3 } & P value & $0.001^{*}$ \\
\hline support FRI out of 28 & Spearman's CC & -0.228 \\
\cline { 2 - 3 } & P value & 0.111 \\
\hline
\end{tabular}

\begin{tabular}{|lll|}
\hline LD group & & \\
\hline support SO out of 28 & Spearman's CC & -0.254 \\
\cline { 2 - 3 } & P value & 0.082 \\
\hline support FAM out of 28 & Spearman's CC & -0.460 \\
\cline { 2 - 3 } & P value & $0.001^{*}$ \\
\hline support FRI out of 28 & Spearman's CC & -0.427 \\
\cline { 2 - 3 } & P value & $0.002^{*}$ \\
\hline
\end{tabular}

*significant $(\mathrm{p}<0.05)$

\section{DISCUSSION}

In the present study there is a comparison of impact that a child having either ADHD, LD or a normal child has on their family and also studied are factors affecting this impact. Impact 
The impact is studied in terms of; parental attitude, marital, social, financial, sibling impact, degree of difficulty living with the child and overall impact. Of these ADHD is found to have a worse impact where parental attitude [9-10]; social [11-13], financial [14-16] and sibling impact [17-19] are concerned, as in keeping with western literature. However, marital impact [20], degree of difficulty living with child [21] and overall impact [22] are at par in both ADHD and LD. This is understandable because Indian parents place an equal premium on both academics and respectful behaviour. This is in contrast to western literature where presumably behaviour is given more weight than academics.

Our finding that hyperactive-impulsive type of $\mathrm{ADHD}$ has more significant negative impact on family in domains of overall impact and degree of difficulty of living with child as compared to inattentive type, most likely owing to the child's externalizing behaviour in the former subtype. The findings of our study are in accordance with literature, which suggests that overall impact worsens with lower socio-economic strata. This finding however is significant only within the ADHD group and not in the LD or non referred group. A significant family environmental risk factor that has been consistently identified as a predictor of a diagnosis of ADHD is low socio-economic strata [23]. When parents have higher levels of income there tends to be more positive parenting strategies leading to a more positive family environment. These findings are similar to the positive correlation shown in our study between low socio-economic strata with increased burden of the disorder.

Parents from higher socio-economic strata displayed better coping, whereas parents from lower socio-economic strata had a negativistic/ indifferent approach (passive strategies) showing poor involvement and poor support towards child [24]. Our results show that overall impact increases in families when one member has ADHD compared with LD and non-referred families and that this stress may be exacerbated as social and financial resources have to be divided when more than one member has the disorder. No significant difference is noticed in LD and no relevant literature was available. Our findings are in keeping with literature for both groups, ADHD and LD, suggesting knowing about their child's disorder indeed helps parents develop more positive parenting practices and thus reducing its overall impact and leading to a healthier family environment.

A negative correlation was found between parent's knowledge of attention deficit hyperactivity disorder \& their stress levels. This finding is in keeping with studies suggesting that strengthening parent's recognition of ADHD is important for reducing parent stress [25]. LD families knowledgeable about their child's disorder have a more positive outlook [26] resulting in a much less negative impact. The positive outlook is either achieved by themselves through positive thinking [27], by actively seeking out help/ psycho-education or by psychological interventions [28-29]. Our findings are in accordance with this. The LD group result is in keeping with literature, suggesting wrong attribution, especially belief in the child's intentionality in causing symptoms, negatively affects the domains of impact in parents. Our result in ADHD is statistically not significant, however a correlation can be seen between parental stress levels are higher if the parents consider the child's behaviour to be intentional.

Wrongful attribution of their child's disorder by parent always causes more negativity in the parent - child relationship. It is usually due to poor knowledge, parents believe their child is intentionally causing the symptoms and so have a much less caring attitude towards child [18], fail to understand their emotional needs and have more erratic parental practices ${ }^{8}$, which in turn affects the child's self-image and behavior adversely [30]. In keeping with literature, our results show that good social support from significant other and family in ADHD lessens the overall impact. The support of those close, especially spouse and family, help lessen the impact while support from friends make no significant difference; curiously though, in LD, social support from significant other shows no significant correlation with overall impact, in keeping with literature, social support of LD parents does show a lesser impact with better social support from family and friends. Parents of children with LD display higher impairment in their social life and poorer social support from their significant others, families and friends [31]. Contrary to literature, LD parents in our study show social support comparable to non-referred population in all three dimensions.

\section{CONCLUSIONS}


The purpose of this study is to examine the presence of family adversity and dysfunction in families having children with ADHD/ LD. Thus we realize that there is significant impact on families of children with ADHD and LD with the former more affected. Perception of social support is also lower in ADHD families. The overall impact on the family of ADHD child is more when the child has hyperactive subtype as opposed to the inattentive subtype, it is a joint family, family members have similar illness, and the family has poor knowledge about illness and when attribution of illness lies within the ambit of child behaviour. This impact is mitigated if there is support from the significant other and family. Hailing from a low socio economic strata makes its difficulty increase. In families with a child of $\mathrm{LD}$, the impact is greater if there is poor knowledge and when attribution of disorder is to perceived child characteristics. Here too, social support from family and friends decreases the negative impact.

\section{CLINICAL IMPLICATIONS}

Whilst assessing the children with either ADHD or LD, it is imperative to assess the family impact and factors affecting them. This would enable help to the affected families improving the quality of life and outcome in both the child and the family. This is especially pertinent in children with ADHD. Thus all professionals dealing with these children need to be sensitized to this aspect to arrest further complications. This also emphasizes the previous findings that upon diagnosis of ADHD, parents need to be educated regarding the resultant dysfunction of the family and the need for utilization of psychological services by the parents as well as the child for increasing positive outcomes with their children, thus reducing the impact of ADHD on families and communities.

\section{REFERENCES}

1. Shah H. Psychosocial aspects of academic failure in children. Health Administrator 2005;26(1):34-7.

2. Cunningham C. A Family-Centered Approach to Planning and Measuring the Outcome of Interventions for Children with Attention-Deficit/Hyperactivity Disorder. Ambulat Pediatr 2007;7:60-72.

3. Strnadová I. Stress and resilience in families of children with specific learning disabilities. Rev Complut 2006;17(2):35-50.

4. Dyson LL. The experiences of families of children with learning disabilities: Parental stress, family functioning, and sibling self-concept. J Learning Disabil 1996;29(3):280-6.

5. Estell DB, Perdue NH. Social support and behavioral and affective school engagement: The effects of peers, parents, and teachers. Psychol Schools 2013;50(4):325-39.

6. Gore N, Hastings R, Brady S. Early intervention for children with learning disabilities: making use of what we know. Tizard Learning Disability Review 2014;19(4):181-9.

7. American Psychiatric Association. Diagnostic and Statistical Manual for the Classification of Psychiatric Disorders $-4^{\text {th }}$ edition text revised (DSM-IVTR). American Psychiatric Publishing ; 2000.

8. Donenberg G, Baker B. The impact of young children with externalizing behaviours on their families. J Abnorm Child Psychol 1993;21(2):179-98.

9. Zimet G., Dahlem N., Zimet S. \&Farley G (1988). The Multidimensional Scale of Perceived Social Support. J Personal Assess 1988;52(1):30-41.

10. Barkley R, Anastopouios A, Guevremont D, Fletcher K. Adolescents with Attention Deficit Hyperactivity Disorder: Mother-Adolescent Interactions, Family Beliefs and Conflicts, and Maternal Psychopathology. J Abnorm Child Psychol 1992;20(3):262-88.

11. Waggoner K, Wilgosh L. Concerns of Families of Children with Learning Disabilities. J Learn Disabil 1990;23: 97-8.

12. Faerstein L. Stress and Coping in Families of Learning Disabled Children - A Literature Review. J Learning Disabil 1981;14(7):420-3.

13. Karande S, Kuril S. Impact Of Parenting Practices On Parent-Child Relationships In Children With Specific Learning Disability. J Postgrad Med 2011;57(1):20-30.

14. Gidron B, Guterman N, Hartman H. Stress and coping patterns of participants and non-participants in selfhelp groups for parents of the mentally ill. Commun Ment Health J 1990:26(6):483-96.

15. Gergen K. The Self as Social Construction. Psychol Stud 2011;56(1):108-16.

16. Blacher J, Begum GF, Marcoulides GA, Baker BL. Longitudinal perspectives of child positive impact on families: Relationship to disability and culture. Am J Intellect Dev Disabil 2013;118(2):141-55. 
17. Heiman T, Berger O. Parents of children with Asperger syndrome or with learning disabilities: Family environment and social support. Res Dev Disabil 2008;29(4):289-300.

18. Heiman T. Parents of Children with Disabilities: Resilience, Coping, and Future Expectations. J Dev Physical Disabil 2002;14(2):159-71.

19. Kendall J. Sibling Accounts of Attention Deficit Hyperactivity Disorder (ADHD). Fam Proc 1999;38:117-36.

20. Stephenson J. The perspectives of mothers whose children are in special day classes for Learning Disabilities .J Learn Disabil 1992;25(10):539-43.

21. Pentyliuk M. Parental perceptions of the effects of Learning Disabilities Assessment on family adaptation. Can J School Psychol 2002;17:15-29.

22. Kashdan T, Jacob R Pelham W, Lang A, Hoza B, Blumenthal J. Depression and Anxiety in parents of children with $\mathrm{ADHD}$ and varying levels of oppositional defiant behaviours: modeling relationships with family functioning. J Clin Child Adolesc Psychol 2004;33(1):169-81.

23. Lardieri L, Blacher J, Swanson H. Sibling relationships and parent stress in families of children with and without learning disabilities. Learning Disabil Quart 2000;23(2):105-16.

24. Baxter C, Cummins R, Yiolotis L. Parental stress attributed to family members with and without disability: A longitudinal study. Australian Society for the Study of Intellectual Disability ; 2000.

25. Foley M, Antshel M, Barkley R. A comparison of family adversity and family dysfunction in families of children with attention deficit hyperactivity disorder (ADHD) and families of children without ADHD. J Spec Pediatr Nurs 2011;16:39-49.

26. Lange G, Sheerin D, Carr A, Dooley B, Barton V, Marshall D. Family factors associated with attention deficit hyperactivity disorder and emotional disorders in children. J Fam Ther 2005;27:76-96.

27. Chronis A, Chacko A, Fabiano G, Wymbs B, Pelham W. Enhancements to the Behavioral Parent Training Paradigm for Families of Children With ADHD: Review and Future Directions. Clin Child Fam Psychol Rev 2004;7(1):1-27.

28. Kim JM, Mahoney G. The effects of relationship focused intervention on Korean parents and their young children with disabilities. Res Dev Disabil 2005;26(2):117-30.

29. Falik L. Family Patterns of Reaction to a Child with a Learning Disability - A Mediational Perspective. J Learning Disabil 1995;28(6):335-41.

30. Paczkowski E, Baker B. Parenting Children With Developmental Delays: The Role Of Positive Beliefs. J Ment Health Res Intellect Disabil 2008;1(3): 156-66.

31. Kale A, Landreth G. Filial therapy with parents of children experiencing learning difficulties. International J Play Ther 1999; 8(2):35-56.

32. Karande S, Mehta V, Kulkarni M. Impact Of an Education Program on Parental Knowledge of Specific Learning Disability. Indian J Med Sci 2007;61(7):398-406.

Acknowledgements - Nil.

Source of Funding - Nil

Conflict of Interest - Nil 